\title{
Current trends in minimally invasive valve-sparing aortic root replacement - best available evidence
}

\author{
Davorin Sef ${ }^{1}$, Toufan Bahrami ${ }^{1}$, Shahzad Raja ${ }^{1}$, and Tomislav Klokocovnik ${ }^{2}$ \\ ${ }^{1}$ Department of Cardiac Surgery Harefield Hospital Royal Brompton and Harefield \\ Hospitals Guy's and St Thomas' NHS Foundation Trust London United Kingdom \\ ${ }^{2}$ Department of Cardiovascular Surgery University Hospital Center Ljubljana Ljubljana \\ Slovenia EU
}

April 1, 2022

\begin{abstract}
Background: Valve-sparing aortic root replacement such as the re-implantation (David) procedure is becoming increasingly popular. Despite the fact that the procedure is technically more complex, long-term studies demonstrated that excellent clinical outcomes in selected patients with durable repair are achievable. Benefits of minimal access cardiac surgery have stimulated enthusiasm in the use of this approach for valve-sparing aortic root replacement. Methods: We have reviewed available literature on the topic of valve-sparing aortic root replacement (David procedure) via minimally invasive approach through upper hemisternotomy in an attempt to assess current trends and to recognize potential advantages of this technique. Patient selection and preoperative work-up play important role in performing minimally invasive David procedure safely. Surgical technique is similar to the standard David procedure, with several exceptions, and is performed via upper hemisternotomy. Results and Conclusion: Evidence from non-randomized observational and comparative studies demonstrated excellent clinical outcomes of minimally invasive David procedure in selected patients with comparable perioperative mortality to the conventional technique. To date, elective David procedure with a minimal access technique has been performed in low- and intermediate-risk patients. We believe that minimally invasive David procedure could be particularly useful in young patients (Marfan syndrome, bicuspid $\mathrm{AV}$ ) as it allows faster recovery with improved cosmesis. A decision to perform minimally invasive David procedure should be individualized to each patient and based on the experience of the team. Further large prospective randomized studies with long-term follow-up are still needed to confirm durability of minimal access technique.
\end{abstract}

Current trends in minimally invasive valve-sparing aortic root replacement - best available evidence

Davorin Sef, MD ${ }^{1}$, Toufan Bahrami, MD, PhD ${ }^{1}$, Shahzad G. Raja, MD, FRCS (C-Th), Tomislav Klokocovnik, MD, PhD, FECTS ${ }^{2}$

${ }^{1}$ Department of Cardiac Surgery, Harefield Hospital, Royal Brompton and Harefield Hospitals, Guy's and St. Thomas' NHS Foundation Trust, London, United Kingdom

${ }^{2}$ Department of Cardiovascular Surgery, University Hospital Center Ljubljana, Ljubljana, Slovenia, EU

Short running title: Minimally invasive David procedure

Funding: There was no funding received for this research.

Conflict of interests: None to declare.

Word count: 3248 
Figures: 1

Tables: 3

References: 25

Corresponding author

Davorin Sef, MD

Department of Cardiac Surgery

Harefield Hospital

Royal Brompton and Harefield Hospitals

Part of Guy's and St. Thomas' NHS Foundation Trust Harefield Hospital

Hill End Road, Harefield, London UB96JH, UK

Email: davorin.sef@gmail.com

\section{Abstract}

Background: Valve-sparing aortic root replacement such as the re-implantation (David) procedure is becoming increasingly popular. Despite the fact that the procedure is technically more complex, long-term studies demonstrated that excellent clinical outcomes in selected patients with durable repair are achievable. Benefits of minimal access cardiac surgery have stimulated enthusiasm in the use of this approach for valve-sparing aortic root replacement.

Methods: We have reviewed available literature on the topic of valve-sparing aortic root replacement (David procedure) via minimally invasive approach through upper hemisternotomy in an attempt to assess current trends and to recognize potential advantages of this technique. Patient selection and preoperative work-up play important role in performing minimally invasive David procedure safely. Surgical technique is similar to the standard David procedure, with several exceptions, and is performed via upper hemisternotomy.

Results and Conclusion: Evidence from non-randomized observational and comparative studies demonstrated excellent clinical outcomes of minimally invasive David procedure in selected patients with comparable perioperative mortality to the conventional technique. To date, elective David procedure with a minimal access technique has been performed in low- and intermediate-risk patients. We believe that minimally invasive David procedure could be particularly useful in young patients (Marfan syndrome, bicuspid AV) as it allows faster recovery with improved cosmesis. A decision to perform minimally invasive David procedure should be individualized to each patient and based on the experience of the team. Further large prospective randomized studies with long-term follow-up are still needed to confirm durability of minimal access technique.

Keywords: valve-sparing aortic root replacement, David procedure, minimally invasive cardiac surgery, aortic root aneurysm, hemisternotomy.

\section{Introduction}

For several decades, the composite replacement with a valved conduit, as first described by Bentall and De Bono, has been a gold standard for the treatment of a combined pathology of the ascending aorta and the aortic valve (AV). ${ }^{1}$ Valve-sparing aortic root replacement such as the re-implantation (David) procedure is becoming increasingly popular, particularly in patients with normal AV function. ${ }^{2}$ One of the major benefits of this technique is that it avoids the disadvantage of composite root replacement including the need for life-long anticoagulation as in mechanical valve conduits or structural valve degeneration with the need of reoperation as in tissue valve conduits. ${ }^{3,4}$. Despite the fact that the procedure is technically more complex, long-term studies demonstrated that excellent clinical outcomes in selected patients are achievable even over the 25-year follow-up period. ${ }^{3,5,6}$ It is evident that excellent surgical outcomes have been a combination 
of careful patient selection and meticulous surgical technique. ${ }^{5}$ As outlined by David and colleagues, AV function slowly deteriorates with the cumulative risk of developing moderate or severe aortic regurgitation (AR) in up to $10.2 \%$ of patients after 20 years, while the cumulative proportion of AV reoperations was reported to be $6.0 \%$ (95\% C.I. $2.8 \%, 12.9 \%)$ after 20 years. ${ }^{5}$ Similarly, Mokashi and colleagues in a cohort of 92 patients reported the freedom from reoperation after the David procedure for tricuspid AV of $98 \%$ at 8 years, whereas it was $77 \%$ for bicuspid AV.$^{7}$ However, despite some studies have raised concerns regarding the lower durability of the David procedure, Leontyev and colleagues demonstrated in their propensitymatched analysis that the David procedure is preferable to the Bentall procedure in patients with appropriate pathoanatomy. ${ }^{8}$ The authors reported similar survival rates and freedom from reoperation after 10 years with lower risk of postoperative bleeding and avoidance of long-term complications related to the use of prosthetic valve. ${ }^{8}$

Benefits of minimally invasive cardiac surgery have stimulated enthusiasm in the use of minimally invasive access for both Bentall procedure and valve-sparing aortic root replacement. ${ }^{9-16}$ Since the first report of minimally invasive aortic valve replacement (AVR) in 1993, minimally invasive access has been associated with comparable operative mortality, less bleeding and reduced intensive care and hospital stay when compared to the conventional sternotomy. ${ }^{11,12,17-20}$ Furthermore, faster recovery, less pain and better cosmesis have been reported in several clinical studies. ${ }^{21-23}$

In this article, we have reviewed all the available literature on the topic of valve-sparing aortic root replacement (David procedure) via minimally invasive access through upper hemisternotomy in an attempt to assess current trends and to recognize potential advantages of this technique. We believe this is the first comprehensive review article to discuss minimally invasive valve-sparing aortic root replacement(David procedure).

\section{Literature search}

Medline, EMBASE databases, and the Cochrane Library were searched from 1992 (date of first David procedure performed) to December 2021 by a librarian. Eligible studies were identified using various combinations of Medical Subject Headings and keywords in the abstract or title: valve-sparing aortic root replacement, David procedure, minimally invasive cardiac surgery, (upper) hemisternotomy. Six retrospective nonrandomized studies from 5 different centers were identified including a total of 250 patients operated via minimal access. Ethics Committee approval was not required as this is a review manuscript. Case reports, conference papers or abstracts and studies not published in languages other than English were excluded.

\section{Patient selection and preoperative assessment}

Recent evidence demonstrates that patient selection plays important role in the long-term outcomes of the David procedure in both conventional and minimally invasive access. ${ }^{5,} 10,13$ Several centers reported how they started performing minimally invasive David procedure in carefully selected elective patients after having experience in performing David procedure via conventional sternotomy. ${ }^{10-13,15}$ In addition, a few studies emphasized the importance of developing fundamental skillset and having experience in minimally invasive AVR beforehand due to the challenges of the learning-curve. ${ }^{10,11,13}$

Shrestha and colleagues reported that they have initially performed minimally invasive David procedure in relatively young patients ( $<60$ years) with isolated aortic root aneurysm, no significant co-morbidities, and AR without leaflet calcifications. ${ }^{10}$ Furthermore, excellent initial outcomes have encouraged performing minimally invasive David procedure in all elective patients with isolated aortic root aneurysm. ${ }^{13}$ However, minimally invasive access was generally not considered in patients with previous sternotomy and those requiring additional concomitant procedures (coronary bypass, valve surgery). ${ }^{10} \mathrm{~A}$ very deep aortic root might represent an anatomical contraindication for minimally invasive access. Still, the final decision whether to proceed with a valve-sparing technique was made by the surgeon intraoperatively after the assessment of AV using transesophageal echocardiography (TOE) and direct inspection. ${ }^{10,13,24}$

Preoperative work-up is another important aspect for performing minimally invasive David procedure 
safely. ${ }^{10,13}$ In addition to routine preoperative assessment, echocardiography, computed tomography scan of aorta and coronary angiography (age $>40$ years) are required..$^{10,13,24}$

\section{Surgical technique}

Surgical technique corresponds to the standard David procedure, with a few exceptions related to the minimal access, and it can be performed without any specialized equipment. ${ }^{2,6,10,13}$ Upper hemisternotomy (down to the $3^{\text {rd }}$ or $4^{\text {th }}$ intercostal space) is performed to approach the aortic root and ascending aorta.Special care is taken to avoid injury of the right internal thoracic artery and vein. Following systemic heparinization, cardiopulmonary bypass $(\mathrm{CPB})$ is established with central cannulation under mild hypothermia $\left(32-34^{\circ} \mathrm{C}\right)$. .It may be easier to achieve venous drainage via superior caval vein cannulation rather than right atrium, as it enables better exposure despite the limited access.Also, some surgeons prefer femoral venous cannulation with the Seldinger technique under echocardiographic guidance to provide better exposure of the operative field. In the case that additional drainage is needed, "Y" femoral venous line can be used. ${ }^{16} \mathrm{~A} \mathrm{CO}_{2}$ insufflation is used. Left heart is vented via the right upper pulmonary vein. After an aortic cross-clamp (ACC) is applied and aortotomy performed, heart is arrested using direct intermittent antegrade cardioplegia (Buckberg, Del Nido or Custodiol). ${ }^{6,10,13}$ As multiple cardioplegia redosing might be time-consuming particularly, Custodiol cardioplegia can be beneficial as a single dose can provide up to 90-120 mins of myocardial protection. ${ }^{16}$

After the transection of the ascending aorta just above the commissures, AV is carefully assessed. Strategically positioned pericardial traction sutures can bring the aorta closer and provide optimal exposure. The aortic root is mobilized in a standard manner, commissural sutures are applied for exposure of the root, and the coronary ostia are excised as buttons (Figure 1). If necessary, aortic valve repair is performed. Sizing of the aortic annulus is performed using Hegar's dilator and graft diameter is determined by using $+2 \mathrm{~mm}$ larger size. Interrupted pledgeted Ethibond 2-0 sutures are applied below the AV from the inside out to anchor the graft. Either the Dacron or Valsalva graft can be used for aortic root replacement. The mobilized aortic root with residual free margins of the aortic sinuses is sutured to the inside of the Dacron graft using continuous 4-0 polypropylene sutures. Cor-Knot can be used for securing the graft to facilitate suturing, particularly in the limited space of a mini-sternotomy, although this technology still requires continued surveillance. ${ }^{16}$

A water-test is performed to assess the coaptation of the reimplanted native AV. Additional AV leaflet repair is performed if needed. The coronary buttons are reinserted using a continuous 5-0 polypropylene suture. Finally, the valve and hemostasis are tested by pressurizing the aortic root with cardioplegia. Meticulous hemostasis is particularly important factor during minimally invasive David procedure.

The distal anastomosis is performed, and the aortic clamp removed after de-airing. AV function is assessed by intraoperative TOE. Complete rewarming of the patient is achieved while in the operating room.

\section{Postoperative management and outcomes}

Patients undergoing minimally invasive David procedure can experience faster recovery as expected after minimally invasive surgery. A summary of perioperative data compared to the full sternotomy groups in several studies is available in a Table 1.Interestingly, Charchyan and colleagues reported significantly decreased intraoperative blood loss $(710 \pm 171 \mathrm{~mL}$ vs. $1065 \pm 288 \mathrm{~mL}, \mathrm{p}=0.001)$, 48-hour postoperative drainage $(317 \pm 101 \mathrm{~mL}$ vs. $647 \pm 300 \mathrm{~mL}, \mathrm{p}=0.001)$, mechanical ventilation time $(5 \pm 1.9 \mathrm{~h}$ vs. $9.2 \pm 1.3 \mathrm{~h}, \mathrm{p}=0.001)$ in the group of patients who underwent minimally invasive procedure when compared to the full sternotomy group. ${ }^{15}$ On the other hand, Shrestha and colleagues reported no difference in mechanical ventilation time, while they observed lower intraoperative need for red blood cells (1.0 $\pm 1.7 \mathrm{vs.} 2.1 \pm 1.8$ units) in the minimally invasive group. ${ }^{10}$ In addition, $65 \%$ of patients could be operated without any blood transfusions. ${ }^{10}$ Similarly, Monsefi and colleagues observed significantly lower need for red blood cells in the minimally invasive group (1.6 \pm 3 vs. $3.7 \pm 6$ units, $\mathrm{p}<0.01)$ when compared to the full sternotomy group. ${ }^{11}$ Immediate perioperative anesthetic management individualized to each patient and early extubation represent important adjuncts in the early postoperative care of these patients. Patients require long-life antiplatelet therapy with aspirin, if not contraindicated. ${ }^{3}$ Repeat transthoracic echocardiography is recommended before discharge. In the event of significant bleeding, re-exploration should be accomplished through the same incision. Importantly, 
re-exploration for bleeding rate was reported to be lower than in the full sternotomy groups across several studies (Table 1.). ${ }^{10,11,15}$

Recent studies reported postoperative clinical outcomes with minimally invasive David procedure comparable to the conventional technique. ${ }^{10-11, ~ 13-16}$ Postoperative outcomes and characteristics of included studies are demonstrated in a Table 2. 30-day mortality was reported between $0 \%$ and $3.3 \%$, although all the published series had a sample size of less than 100 patients. ${ }^{10-11,}$ 13-16 Furthermore, selection of patients might have positively influenced outcomes as minimal access was performed in elective patients with noncalcified aortic valves. Notably, Marfan syndrome was reported in 3.9-18.8\% of patientswhile patients with bicuspid AV in 7.7-38.7\% of patients. ${ }^{10-11,13-16}$ As these patients present at relatively young age, Shrestha and colleagues report that it could be beneficial to provide minimal accesssurgery as cosmesis is considered an important factor by these younger patients. ${ }^{10}$ In addition, it also has the potential to enable faster return to normal activities which is another important factor for younger patients. ${ }^{25}$

Aortic cross clamp and CPB time ranged from 110.6 to 168.5 minutes and from 139 to 199.5 minutes, respectively. ${ }^{10-11,13-16}$ Charchyan and colleagues reported significantly longer ACC and CPB time in the minimally invasive when compared to the full sternotomy group after matching ( $147 \pm 14$ vs. $134 \pm 31$ mins, $\mathrm{p}=0.044 ; 130 \pm 17$ vs. $115 \pm 21$ mins, $\mathrm{p}=0.004$ respectively), while Shrestha and colleagues found longer ACC and CPB time although the difference was not significant (115.6 \pm 30.3 vs $114.1 \pm 19.9$ mins, $175 \pm 8$ vs. $163 \pm 24.5$ mins, respectively). ${ }^{10}, 15$ On the other hand, Shah and colleagues found no significant differences in ACC and CPB time when compared to the full sternotomy group (169 [155-179] vs. 188 [155-199] min, $\mathrm{p}=0.128)$; $(200$ [183-208] vs. 212 [183-223] min, $\mathrm{P}=0.309$, respectively). However, they have used significantly more Cor-Knot (100\% vs. $0 \%$ ) and Custodiol cardioplegia (94\% vs. $37 \%$ ) in the minimally invasive group to facilitate the procedure and this can explain why the timings were not prolonged in the minimally invasive group. ${ }^{16}$ However, it seems that this has not negatively influenced postoperative clinical outcomes. Several studies reported decreased requirements for blood products, relatively shorter ICU length of stay (1.1-3 days) and low 30-day stroke rate (0-3.3\%). ${ }^{10,11,15}$ Despite the fact that most centers emphasized importance of meticulous hemostasis, re-exploration for bleeding was reported up to $9 \%$ in some of the studies. ${ }^{10,11,13}$ Excellent early echocardiographic outcomes were reported in most studies with postoperative aortic insufficiency (AI) [?]1 observed in 84.6-100\% of patients. ${ }^{10}, 11,13,14,16$ Monsefi and colleagues reported echocardiographic results at mid-term follow-up (3+-2 years) and demonstrated excellent findings in $99 \%$ of patients, while only one patient had to be reoperated due to severe AI. ${ }^{11}$ In addition, Hou and colleagues observed that 2 (4.5\%) of patients developed moderate or severe AI during the cumulative follow-up of $9+-7.8$ months. ${ }^{14}$

In summary, our review of available literature on the topic of minimally invasive David procedure demonstrated that minimally invasive access could facilitate recovery of selected elective patients with isolated aortic root aneurysm along with similar early postoperative outcomes to conventional surgery. However, there are many potential pitfalls in minimally invasive David procedure and recent studies highlighted challenges of the learning curve. Sufficient experience at centers with adequate case volumes in both conventional aortic root surgery and minimal access AVR are necessary before progressing to the next step to avoid potential vulnerability and performance obstacles.

\section{Limitations of studies}

Limitations of this study are related to several limitations of the included studies. Firstly, available literature remains limited and data are derived from observational retrospective studies of relatively small cohorts of patients. Several studies included the control group of patients who underwent full sternotomy for a comparison; however, these groups of patients were not truly comparable in several aspects as they included patients with combined procedures and are biased with selection of patients for the minimally invasive David procedure. In addition, improved surgeon's experience with the minimal access during the study period might have influenced outcomes, particularly timings of surgery. Furthermore, one of main limitations of these studies is that we still do not have available long-term follow-up data with echocardiographic findings. Interestingly, Monsefi and colleagues reported mid-term results with a mean follow-up of $3+-2$ years with 
completeness of $96 \% .{ }^{11}$ Importantly, they reported 5-year freedom from reoperation of $93 \%$ and $0 \%$ late mortality in their series with unremarkable predischarge echocardiographic findings in $99 \%$ of patients. ${ }^{11}$ However, the results were not propensity matched to the full sternotomy group as there were significantly more patients with type A aortic dissection ( $14 \%$ vs. $4 \%, \mathrm{p}=0.03)$ and concomitant coronary artery bypass grafting (CABG) in the conventional group $(21 \%$ vs. $4 \%, \mathrm{p}<0.01) .{ }^{11}$

Two studies included propensity-matched analysis; however, these studies included carefully selected patients with many patients exclude from analysis. ${ }^{14,15}$ While Charchyan and colleagues compared their results to 30 matched patients who underwent full sternotomy, they also included a significant number of patients with combined procedures which could influence outcomes (arch replacement $6.6 \%$ vs $9.9 \%$, CABG 0\% vs $9.9 \%$, mitral valve reconstruction $9.9 \%$ vs $6.6 \%) .{ }^{15}$ They provide mid-term results with a mean followup of 13.8+-10.3 months in the minimally invasive group, but unfortunately they did not report followup echocardiographic findings. ${ }^{15}$ Similarly, Hou and colleagues matched their results to 52 patients who underwent full sternotomy; however, they excluded around 21\% (52 out of 269) of patients from their study. ${ }^{14}$ They also included patients with combined procedures in their propensity-matched analysis when compared to the full sternotomy group $(7.7 \%$ vs. $11.5 \%) .{ }^{14}$ However, one of the strengths of their study is that they provided echocardiographic data after the average cumulative follow-up of 9 months, although with completeness of $91 \% .^{14}$

Further large prospective randomized studies with long-term follow-up are still needed to confirm durability of minimal access technique and to investigate for which subgroups of patients this technique could be particularly useful.

\section{Ljubljana experience}

At the University Hospital Center Ljubljana (Slovenia, EU), 16 patients (12 male) with isolated aortic root aneurysm were selected for minimally invasive David procedure over a 4-year period (Figure 1). No Ethics Committee approval was required given that this analysis was retrospective and anonymized. All patients were consented for the surgery and use of their anonymized data for future research and publications.

Concomitant aortic valve repair was performed in 8 out of 16 (50\%) patients and coronary artery bypass graft (saphenous venous graft to right coronary artery) in one patient. In most cases, straight 30-32 mm Dacron graft (Gelweave) was used. Technique was also modified by performing wrapping of distal anastomosis in 10 out of 16 patients as, in our experience, it was helpful in achieving better hemostasis. No conversion to full sternotomy or re-exploration due to bleeding was observed. 30-day postoperative mortality and stroke were $0 \%$.

\section{Conclusions}

Several non-randomized observational and comparative studies demonstrated excellent clinical outcomes of minimally invasive David procedure in selected patients with comparable perioperative mortality to the conventional technique. To date, elective David procedure with a minimal access technique has been performed in carefully selected patients. We believe that it could be particularly beneficial to provide younger patients (Marfan syndrome, bicuspid AV) with minimally invasive David procedure as it can allow faster recovery with improved cosmesis with excellent outcomes. A decision to perform minimally invasive David procedure should be individualized to each patient and based on the experience of the team. Further large prospective randomized studies with long-term follow-up are still needed to confirm durability of minimal access technique and to investigate whether this technique can be useful for other subgroups of patients (high-risk, need for aortic valve repair).

Ethical approval: Not directly applicable since this is a review paper. The authors confirm that written consent for submission and publication of patient's intraoperative image has been obtained from the patient in line with COPE guidance.

Author contributions: Davorin Sef: conceptualization, formal analysis, investigation, methodology, validation, resources, writing - original draft, critical revision and approval of the article. Toufan Bahrami, 
Shahzad G. Raja, Tomislav Klokocovnik: conceptualization, formal analysis, validation, resources, supervision, writing - reviewing and editing.

\section{Data Availability Statement}

Data available on request due to privacy/ethical restrictions.

\section{Acknowledgments: None.}

\section{FIGURE LEGENDS}

Figure 1. Exposure of the aortic root via upper hemisternotomy and sizing of the aortic annulus. Written informed consent to publication was provided by the patient.

\section{References}

1. Bentall H, De Bono A. A technique for complete replacement of the ascending aorta. Thorax. $1968 ; 23(4): 338-9$.

2. David TE, Feindel CM. An aortic valve-sparing operation for patients with aortic incompetence and aneurysm of the ascending aorta. J Thorac Cardiovasc Surg. 1992;103(4):617-21.

3. Beckmann E, Martens A, Kruger H, et al. Aortic valve-sparing root replacement with Tirone E. David's reimplantation technique: single-centre 25-year experience. Eur J Cardiothorac Surg. 2021;60(3):642-8.

4. Monsefi N, Miskovic A, Moritz A, Zierer A. Long-term results of the David Procedure in patients with acute type A aortic dissection. Int J Surg. 2015;22:99-104.

5. David TE, David CM, Ouzounian M, Feindel CM, Lafreniere-Roula M. A progress report on reimplantation of the aortic valve. J Thorac Cardiovasc Surg. 2021;161(3):890-9.e1.

6. Shrestha M, Baraki H, Maeding I, et al. Long-term results after aortic valve-sparing operation (David I). Eur J Cardiothorac Surg. 2012;41(1):56-61.

7. Mokashi SA, Rosinski BF, Desai MY, et al. Aortic root replacement with bicuspid valve reimplantation: Are outcomes and valve durability comparable to those of tricuspid valve reimplantation? $J$ Thorac Cardiovasc Surg. 2022 Jan;163(1):51-63.e5.

8. Leontyev S, Schamberger L, Davierwala PM, et al. Early and Late Results After David vs Bentall Procedure: A Propensity Matched Analysis. Ann Thorac Surg. 2020;110(1):120-6.

9. Klokocovnik T. Direct minimally invasive approach for aortic root replacement. J Cardiovasc Surg (Torino). 2002;43(4):475-7.

10. Shrestha M, Krueger H, Umminger J, et al. Minimally invasive valve sparing aortic root replacement (David procedure) is safe. Ann Cardiothorac Surg. 2015;4(2):148-53.

11. Monsefi N, Risteski P, Miskovic A, Moritz A, Zierer A. Midterm Results of a Minimally Invasive Approach in David Procedure. Thorac Cardiovasc Surg. 2018;66(4):301-6.

12. Hillebrand J, Alshakaki M, Martens S, Scherer M. Minimally Invasive Aortic Root Replacement with Valved Conduits through Partial Upper Sternotomy. Thorac Cardiovasc Surg. 2018;66(4):295-300.

13. Beckmann E, Martens A, Krueger H, Kaufeld T, Haverich A, Shrestha MJJoVS. Aortic valve sparing aortic root replacement (David procedure) via an upper hemisternotomy: Hannover experience. $J$ Vis Surg. $2021 ; 7: 3$.

14. Hou B, Zhao R, Wang D, et al. Outcomes of the Valve-Sparing Root Replacement Procedure with Partial Upper Sternotomy. J Cardiovasc Dev Dis. 2021; 8(11):154. 
15. Charchyan ER, Breshenkov DG, Belov YV. Results of Minimally Invasive Valve-Sparing Aortic Root Valve Surgery: Propensity Score Matching Analysis. Kardiologiia. 2020;60(7):91-7.

16. Shah VN, Kilcoyne MF, Buckley M, Orlov OI, Sicouri S, Plestis KA. How We Perform a David Procedure With an Upper Hemisternotomy Approach. Innovations (Philadelphia). 2021;16(6):545-52.

17. Rao PN, Kumar AS. Aortic valve replacement through right thoracotomy. Tex Heart Inst J. $1993 ; 20(4): 307-8$.

18. Murtuza B, Pepper JR, Stanbridge RD, et al. Minimal access aortic valve replacement: is it worth it? Ann Thorac Surg. 2008;85(3):1121-31.

19. Sef D, Krajnc M, Klokocovnik T. Minimally invasive aortic valve replacement with sutureless bioprosthesis through right minithoracotomy with completely central cannulation-Early results in 203 patients. J Card Surg. 2021;36(2):558-64.

20. Brown ML, McKellar SH, Sundt TM, Schaff HV. Ministernotomy versus conventional sternotomy for aortic valve replacement: a systematic review and meta-analysis. J Thorac Cardiovasc Surg. 2009;137(3):670-9 e5.

21. Mariscalco G, Musumeci F. The minithoracotomy approach: a safe and effective alternative for heart valve surgery. Ann Thorac Surg. 2014;97(1):356-64.

22. Lamelas J. Minimally invasive aortic valve replacement: the "Miami Method". Ann Cardiothorac Surg. 2015;4(1):71-7.

23. Bonacchi M, Prifti E, Giunti G, Frati G, Sani G. Does ministernotomy improve postoperative outcome in aortic valve operation? A prospective randomized study. Ann Thorac Surg. 2002;73(2):460-5.

24. Chirichilli I, Irace FG, D'Aleo S, et al. Long-term follow-up of Bentall procedure using the Perimount bioprosthesis and the Valsalva graft. Interact Cardiovasc Thorac Surg. 2020;30(5):679-84.

25. Brown ML, McKellar SH, Sundt TM, Schaff HV. Ministernotomy versus conventional sternotomy for aortic valve replacement: a systematic review and meta-analysis. J Thorac Cardiovasc Surg 2009;137:6709.e5.

Table 1. Characteristics of included studies.

\begin{tabular}{|c|c|c|c|c|c|c|}
\hline Study name & $\begin{array}{l}\text { Shrestha M } \\
\text { et al. }{ }^{10}\end{array}$ & $\begin{array}{l}\text { Monsefi et } \\
\text { al. }{ }^{11}\end{array}$ & $\begin{array}{l}\text { Charchyan } \\
\text { et al. }{ }^{15}\end{array}$ & $\begin{array}{l}\text { Beckmann et } \\
\text { al. }{ }^{13}\end{array}$ & Hou et al. ${ }^{14}$ & Shah et al. ${ }^{16}$ \\
\hline Year & 2015 & 2018 & 2020 & 2021 & 2021 & 2021 \\
\hline Country & Germany & Germany & Russia & Germany & China & USA \\
\hline Study design & $\begin{array}{l}\text { Retrospective } \\
\text { comparative }\end{array}$ & $\begin{array}{l}\text { Retrospective } \\
\text { comparative }\end{array}$ & $\begin{array}{l}\text { Retrospective } \\
\text { PSM }\end{array}$ & $\begin{array}{l}\text { Retrospective } \\
\text { observational }\end{array}$ & $\begin{array}{l}\text { Retrospective } \\
\text { PSM }\end{array}$ & $\begin{array}{l}\text { Retrospective } \\
\text { comparative }\end{array}$ \\
\hline Study period & 2011-2014 & $1991-2015$ & 2016-2019 & 2011-2018 & 2016-2021 & $2015-2019$ \\
\hline $\mathrm{N}$ of patients & $26^{+}$ & 90 & 30 & 62 & 52 & 16 \\
\hline Age (yrs) & $47.6 \pm 13$ & $57 \pm 14$ & $44.4 \pm 14.5$ & $48.5 \pm 12.1$ & $45.9 \pm 12.1$ & $51.1 \pm 11.9$ \\
\hline $\begin{array}{l}\text { Marfan } \\
\text { syndrome }\end{array}$ & $1(3.9)$ & $9(10)$ & $5(17)$ & $6(9.7)$ & $5(9.6)$ & $3(18.8)$ \\
\hline $\begin{array}{l}\text { Bicuspid } \\
\text { aortic valve }\end{array}$ & $10(38.5)$ & $16(18)$ & $3(10)$ & $24(38.7)$ & $4(7.7)$ & $2(12.5)$ \\
\hline $\begin{array}{l}\text { CPB time } \\
\text { (mins) }\end{array}$ & $175.8 \pm 41.9$ & $188 \pm 48$ & $147 \pm 14$ & $191.4 \pm 39$ & $139 \pm 30.9$ & $\begin{array}{l}199.5(182.5- \\
208)^{*}\end{array}$ \\
\hline $\begin{array}{l}\text { ACC time } \\
(\text { mins })\end{array}$ & $115.6 \pm 30.3$ & $138 \pm 32$ & $130 \pm 17$ & $126.4 \pm 28.8$ & $110.6 \pm 19.9$ & $\begin{array}{l}168.5(154.5- \\
179)^{*}\end{array}$ \\
\hline
\end{tabular}




\begin{tabular}{lllllll}
$\begin{array}{l}\text { Concomitant } \\
\text { aortic leaflet } \\
\text { repair }\end{array}$ & $11(42.3)$ & $44(49)$ & $\mathrm{n} / \mathrm{a}$ & $30(48)$ & $\mathrm{n} / \mathrm{a}$ & $\mathrm{n} / \mathrm{a}$ \\
$\begin{array}{l}\text { Re- } \\
\text { exploration } \\
\text { for bleeding }\end{array}$ & $1(7.1)$ & $8(9)$ & $0(0)$ & $5(8.1)$ & $0(0)$ & $1(6.3)$ \\
$\begin{array}{l}\text { 30-day } \\
\text { stroke }\end{array}$ & $0(0)$ & $1(1)$ & $1(3.3)$ & $1(1.6)$ & $\mathrm{n} / \mathrm{a}$ & $0(0)$ \\
$\begin{array}{l}\text { 30-day } \\
\text { mortality }\end{array}$ & $0(0)$ & $0(0)$ & $1(3.3)$ & $1(1.6)$ & $0(0)$ & $0(0)$ \\
$\begin{array}{l}\text { ICU stay (d) } \\
\text { Hospital } \\
\text { stay (d) }\end{array}$ & $1.3 \pm 0.6$ & $1.1 \pm 0.5$ & $1.2 \pm 0.4$ & $1.8 \pm 1.4$ & $2.1 \pm 1.3$ & $3(2-3.5)^{*}$ \\
\hline
\end{tabular}

Data are presented as count $(\%)$ or mean \pm SD. ${ }^{*}$ median $(\mathrm{IQR}),+$ patients included also in the study by Beckmann et al.Abbreviations: ACC, aortic cross clamp; CPB, cardiopulmonary bypass; d, day; ICU, intensive care unit; N, number; n/a, not applicable

Table 2. Summary of perioperative data (minimally invasive versus full sternotomy groups)

\begin{tabular}{|c|c|c|c|c|c|}
\hline$\overline{\text { Study name }}$ & $\begin{array}{l}\text { Shrestha } \mathrm{M} \text { et al. }{ }^{10} \\
\text { MS }\end{array}$ & $\begin{array}{l}\text { Monsefi et al. }{ }^{11} \\
\text { FS }\end{array}$ & $\begin{array}{l}\text { Charchyan et } \text { al. }^{15} \\
\text { MS }\end{array}$ & $\begin{array}{l}\text { Hou et al. }{ }^{14} \\
\text { FS }\end{array}$ & \\
\hline $\mathrm{N}$ of patients & 26 & 14 & 90 & 206 & 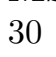 \\
\hline \multicolumn{6}{|l|}{ Concomitant procedures } \\
\hline Hemiarch replacement & $4(15.4)$ & $6(42.9)$ & $9(19)$ & $55(22.7)$ & \\
\hline Total arch replacement & 0 & 0 & $10(11)$ & $8(4)$ & \\
\hline Frozen elephant trunk & 0 & 0 & $5(6)$ & $9(4)$ & \\
\hline CABG & $1(3.9)$ & 0 & $4(4)$ & $43(21)$ & \\
\hline CPB time (mins) & $175.8 \pm 41.9$ & $163 \pm 24.5$ & $188 \pm 48$ & $198 \pm 42$ & \\
\hline ACC time (mins) & $115.6 \pm 30.3$ & $12.2 \pm 8.5$ & $138 \pm 32$ & $146 \pm 31$ & \\
\hline Intraoperative RBC (units) & $1.0 \pm 1.7$ & $2.1 \pm 1.8$ & $1.6 \pm 3$ & $3.7 \pm 6$ & \\
\hline Mechanical ventilation $(\mathrm{h})$ & $12 \pm 7.2$ & $14.4 \pm 16.8$ & $\mathrm{n} / \mathrm{a}$ & $\mathrm{n} / \mathrm{a}$ & \\
\hline Re-exploration for bleeding & $1(3.2)$ & $1(7.1)$ & $8(9)$ & $26(13)$ & \\
\hline Wound infection & $\mathrm{n} / \mathrm{a}$ & $\mathrm{n} / \mathrm{a}$ & $0(0)$ & $0(0)$ & \\
\hline 30-day stroke & $0(0)$ & $0(0)$ & $1(1)$ & $2(1)$ & \\
\hline 30-day mortality & $0(0)$ & $0(0)$ & $0(0)$ & $6(3)$ & \\
\hline ICU stay (d) & $1.3 \pm 0.6$ & $2.1 \pm 1.5$ & $1.1 \pm 0.5$ & $1.8 \pm 2.9$ & \\
\hline Hospital stay (d) & $10.4 \pm 6.8$ & $9.1 \pm 2.7$ & $9 \pm 4$ & $\mathrm{n} / \mathrm{a}$ & \\
\hline
\end{tabular}

Data are presented as count (\%) or mean \pm SD. * median (IQR), +Propensity score matching, Abbreviations: ACC, aortic cross clamp; CPB, cardiopulmonary bypass; d, day; FS, full sternotomy; ICU, intensive care unit; N, number; MS, mini-sternotomy; n/a, not applicable

Table 3. Early echocardiographic data 


\section{Study name}

AI [?] 1

$\mathrm{AI}=2$

$\mathrm{AI}=3-4$

$\mathrm{AV}$ mean gradient $(\mathrm{mmHg})$
Shrestha $\mathrm{M}$ et al. ${ }^{10} \quad$ Monsefi et al. ${ }^{\text {a11 }}$ $22(84.6)$

$4(15.4)$

0

$\mathrm{n} / \mathrm{a}$ $86(99)^{\mathrm{b}}$

0

$1(1)$
Beckmann et al. *13 $22(84.6)$

$4(15.4)$

0

$\mathrm{n} / \mathrm{a}$
Hou et al. ${ }^{14}$ 35 (94.6) $2(5.4)$ 0

$\mathrm{n} / \mathrm{a}$
Shah $16(10$ 0

$\mathrm{n} / \mathrm{a}$

Data are presented as count $(\%)$ or mean $\pm \mathrm{SD} ;{ }^{\mathrm{a}}$ mid-term follow-up data; ${ }^{\mathrm{b}}$ one patient was successfully reoperated due to severe postoperative AI); Abbreviations: AI, aortic insufficiency; AV, aortic valve; n/a, not applicable

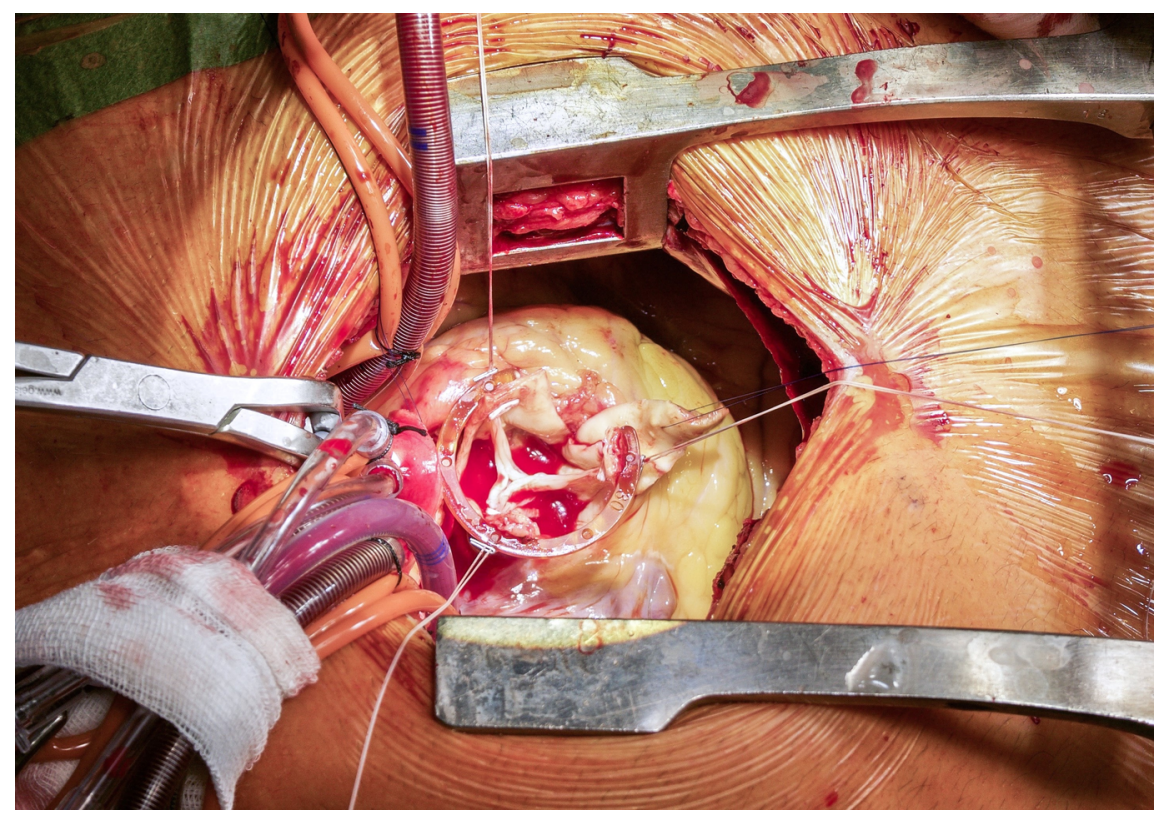

